\title{
Effect of dietary supplementation with fish oil lipids on mild asthma
}

\author{
JONATHAN P ARM, CLAIRE E HORTON, JEAN-MICHEL MENCIA-HUERTA, \\ FRANK HOUSE, NOEMI M EISER, TIM J H CLARK, BERND W SPUR, TAK H LEE
}

From the Departments of Medicine, Respiratory Medicine, and Pharmacology, United Medical and Dental Schools, Guy's Hospital, and the Chest Clinic, Lewisham Hospital, London; and the Institut Henri Beaufour, Les Ulis, France

ABSTRACT Recruitment of inflammatory leucocytes to the airways may play a part in the pathogenesis of asthma. As dietary enrichment with fish oil lipids can suppress leucocyte function, the effect of these lipids on asthma control and neutrophil function was studied in 20 subjects with mild asthma. Twelve subjects received capsules containing $3.2 \mathrm{~g}$ of eicosapentaenoic acid and $2.2 \mathrm{~g}$ of docosahexaenoic acid daily and eight subjects received placebo capsules containing olive oil for 10 weeks in a double blind fashion. Baseline specific airways conductance, airways responsiveness to histamine and exercise, diurnal peak expiratory flow, symptom scores, and bronchodilator use were measured. Neutrophil fatty acid composition was evaluated by gas chromatography, calcium ionophore induced neutrophil leukotriene (LT) $B_{4}$ and LTB $_{5}$ generation were measured by reverse phase high performance liquid chromatography and radioimmunoassay, and neutrophil chemotactic responses to formyl-methionyl-leucyl-phenylalanine (FMLP) and LTB $_{4}$ were assessed by a microchemotaxis technique. Although the fish oil supplemented diet produced a greater than 10 fold increase in the eicosapentaenoic acid content of neutrophil phospholipids, there was no significant change in airways responsiveness to histamine or any change in any of the clinical measurements. After dietary supplementation with fish oil there was a $50 \%$ inhibition of total LTB $\left(\mathrm{LTB}_{4}+\mathrm{LTB}_{5}\right)$ generation by ionophore stimulated neutrophils and neutrophil chemotaxis was substantially suppressed. Neutrophil function remained unchanged in the placebo group. It is concluded that in subjects with mild asthma a fish oil enriched diet attenuates neutrophil function without changing the severity of asthma.

Asthma is characterised by airways inflammation, by bronchial hyperresponsiveness to non-specific stimuli, and by episodic and reversible airflow obstruction. Studies both in experimental animals and in man have indicated an association between airways hyperresponsiveness and bronchial inflammation..$^{1-9}$ It has been suggested that airway inflammation may be central to the pathophysiology of bronchial asthma.

Eicosapentaenoic acid and docosahexaenoic acid are polyunsaturated fatty acids derived from fish oil. They are termed omega-3 $\left(\omega_{3}\right)$ or N-3 fatty acids because the first double bond in the molecule is three carbons removed from the terminal methyl group. These fatty acids competitively inhibit the formation

Address for reprint requests: Dr Tak H Lee, Department of Medicine, Guy's Hospital, London SE1 9RT

Accepted 11 November 1987 of prostaglandins and leukotrienes derived from arachidonic acid (N-6 fatty acid) ${ }^{10-12}$ and eicosapentaenoic acid acts as a substrate for the biosynthesis of prostaglandins with three double bonds and leukotrienes with five double bonds (fig 1). Thus eicosapentaenoic acid is metabolised by the cyclo-oxygenase pathway to thromboxane $A_{3}$ and prostaglandin (PG) $\mathrm{I}_{3}{ }^{13}$ and by the 5-lipoxygenase pathway to leukotriene (LT) $C_{5}$, LTD $_{5}$, LTE $_{5}$, and LTB ${ }_{5}{ }^{14-16}$ Thromboxane $A_{3}$ and LTB $_{5}$ have diminished biological activities, whereas $\mathrm{PGI}_{3}, \mathrm{LTC}_{5}, \mathrm{LTD}_{5}$, and $\mathrm{LTE}_{5}$ are equipotent with their counterparts derived from arachidonic acid..$^{13-17}$ Neutrophils and monocytes obtained from normal subjects who have ingested marine lipids in the form of Max-EPA show an attenuated production of $\mathrm{LTB}_{4}$ after calcium ionophore stimulation, diminished in vitro chemotactic responsiveness to $\mathrm{LTB}_{4}$, and a substantial inhibition of their capacity to adhere to endothelial monolayers pretreated with $\mathrm{LTB}_{4}{ }^{18}$ Thus 

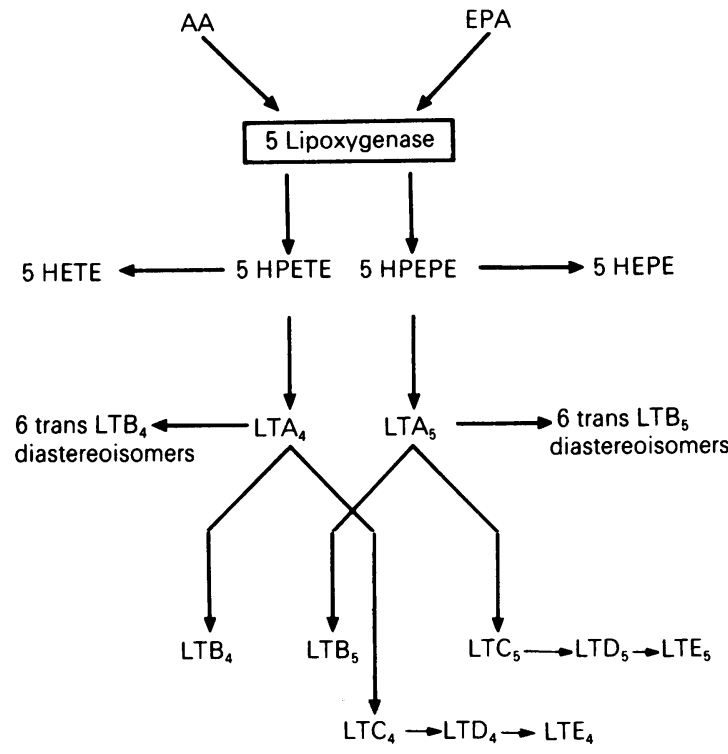

Fig 1 Metabolism of arachidonic acid $(A A)$ and eicosapentaenoic acid (EPA) by the 5-lipoxygenase pathway. 5 HETE-5-hydroxyeicosatetraenoic acid;

5 HPETE-5-hydroperoxyeicosatetraenoic acid;

5 HEPE-5-hydroxyeicosapentaenoic acid;

5 HPEPE-5-hydroperoxyeicosapentaenoic acid;

LT-leukotriene.

dietary supplementation with fish oil lipids has antiinfammatory potential as indicated by its suppression of neutrophil function: In the $N Z B$ mouse model of systemic lupus erythematosus a fish oil enriched diet reduced renal inflammation and proteinuria and prolonged survival without changing the titre of antiDNA antibody. ${ }^{192}$ In man a fish oil supplemented diet was beneficial in rheumatoid arthritis. ${ }^{21}$

Since bronchial inflammation may be important in the pathogenesis of asthma, we have investigated the effects of a diet with the potential to suppress leucocyte function on non-specific airways hyperresponsiveness and the severity of asthma.

\section{Methods}

\section{STUDY DESIGN}

Twenty five asthmatic subjects ( 10 male and 15 female) aged 15-42 years (mean 27 years), 22 of whom were atopic, entered this double blind and placebo controlled study. Eleven subjects were taking regular inhaled corticosteroids, one subject was taking a long ${ }^{3}$ acting oral theophylline preparation at night, and all subjects used inhaled $\beta_{2}$ adrenergic agonists as required. No one was taking an oral corticosteroid, and no one gave a history of aspirin sensitivity. All subjects gave informed consent and the study was approved by the Guy's Hospital ethical committee.

The study began with an initial run in period of two to four weeks, during which diary card records were kept, and a baseline exercise or histamine challenge test (or both) was performed. During this period peripheral blood neutrophils were purified for analysis of fatty acid composition and evaluation of function: calcium ionophore induced generation of leukotriene B compounds ( $\mathrm{LTB}_{4}$ and $\mathrm{LTB}_{5}$ ), and assessment of chemotactic responsiveness to formyl-methionylleucyl-phenylalanine (FMLP) and LTB $_{4}$. Subjects were then randomised to receive 18 capsules a day of Max-EPA (3.2 g eicosapentaenoic acid and 2.2 g docosahexaenoic acid) or identical placebo capsules containing olive oil for 10 weeks. Their usual diets were unchanged. Diary cards were filled in throughout the study period. At the end of the 10 week study, exercise and histamine challenge tests were repeated and neutrophil fatty acid composition and function were assessed again. Inhaled $\beta_{2}$ agonists and inhaled steroids were withheld for 12 hours and oral theophylline for 48 hours before each exercise and histamine challenge test. Subjects who had a skinprick test reaction to mixed grassipollen of $3 \mathrm{~mm}$ or greater than the saline control were not studied during MaySeptember, and subjects with a positive skinprick test reaction to Dermatophagoides pteronyssinus were not studied during September-December.

\section{DIARY CARDS}

Symptoms of nocturnal cough, nocturnal wheeze, and daytime wheeze were assesssed separately by the subjects every day on a scale of 0 (symptom free) to 3 (severe). Daily medication was also recorded. Subjects were instructed in the correct use of a Wright's mini peak flow meter and they recorded the best of three peak flow measurements morning and evening. Symptom scores, morning and evening expiratory peak flow rates, and bronchodilator use in the last two weeks of the control period were compared with those observed in the last two weeks of the treatment period. Symptom scores and the number of doses of bronchodilator used during each two week assessment period were summed separately. Morning and evening peak flow rates were averaged for each two week assessment period. In addition, the difference between morning and evening peak flow rates on each day was expressed as a percentage of the higher figure and used as a measure of airways lability. The average airways lability for each of the two week assessment periods was calculated.

\section{EXERCISE CHALLENGE}

Patients who gave a clear history of exercise induced asthma were subjected to a cycle ergometer exercise. 
They wore a nose clip and undertook eight minutes of exercise on a mechanically braked bicycle ergometer at 60-130 watts (Body Guard 990, Ogloend, Norway). The work load was adjusted to produce about $80 \%$ of maximal predicted oxygen consumption. The exercise was undertaken at ambient temperature and humidity. The pulse rate was measured before and at one minute intervals during exercise. Specific airways conductance (sGaw) was measured before exercise and 5, 10 , $15,30,45$, and 60 minutes after exercise.

\section{HISTAMINE CHALLENGE}

Inhalation challenge was performed with a Hudson nebuliser linked to a breath activated dosimeter. ${ }^{22}$ Delivery of air to the nebuliser was regulated to a pressure of $149 \mathrm{kPa}\left(20 \mathrm{lb} / \mathrm{in}^{2}\right)$ for 0.6 second from the start of each inspiration. After baseline measurements of sGaw subjects inhaled five breaths of phosphate buffered saline. If the decrease in sGaw was under $10 \%$ the patients were subjected to histamine challenge. Two fold increases in the concentration of histamine acid phosphate (Sigma, Dorset) diluted in phosphate buffered saline were inhaled from a starting concentration of $0.5 \mathrm{mg} / \mathrm{ml}$. sGaw was measured at two minute intervals after each inhalation of histamine and increasing concentrations of histamine were administered until a greater than $35 \%$ fall in sGaw was achieved. The cumulative dose of histamine required to produce a $35 \%$ fall in sGaw (histamine $\mathrm{PD}_{35} \mathrm{sGaw}$ ) was determined by linear interpolation from the histamine log dose-response curve.

\section{MEASUREMENTS OF SGAW}

Measurements of sGaw were made in a total body plethysmograph linked to a digital computer. ${ }^{23}$ Four to six measurements of sGaw were recorded at each time point and the mean value was calculated. Baseline sGaw was over $0.9 \mathrm{~s}^{-1} \mathrm{kPa}^{-1}$ before each challenge.

\section{NEUTROPHIL STUDIES}

Neutrophils were purified from $20 \mathrm{ml}$ of anticoagulated peripheral blood to more than $95 \%$ by means of dextran sedimentation (Pharmacia, Bucks) and centrifugation on a cushion of Lymphoprep (Nyegaard, Birmingham). ${ }^{24} \mathrm{~A}$ portion of $2 \times 10^{7}$ cells was resuspended in $800 \mu$ l of distilled water and stored under argon at $-70^{\circ} \mathrm{C}$ before extraction of phospholipids. Neutrophil phospholipids were extracted by the method of Bligh and Dyer. ${ }^{25}$ Samples were first extracted in chloroform (BDH, Dorset). After being dried under a steady stream of nitrogen they were resuspended in boron trifluoride (Sigma) and heated to $100^{\circ} \mathrm{C}$ under nitrogen for 90 minutes to esterify the fatty acids. Samples were then cooled, extracted into hexane (BDH), and stored at $-70^{\circ} \mathrm{C}$ under nitrogen before analysis for fatty acid composi- tion by gas chromatography. ${ }^{19}$

After the removal of neutrophils for lipid extrac- $\bar{C}$ tion, the remaining cells were used whenever possible $\overline{\bar{\sigma}}$ for assessment of chemotactic responses to FMLP $\frac{\bar{\sigma}}{\partial}$ (Sigma) and $\mathrm{LTB}_{4}$, and for measurement of the $\stackrel{\mathbb{Q}}{\varrho}$ quantities of $\mathrm{LTB}_{4}$ generated by neutrophils stimulated by calcium ionophore (A23187) (Calbio- $\vec{\circ}$ chem, La Jolla, California) under optimal conditions. Chemotaxis was assessed by a microchemotaxis $\vec{\omega}$ method. ${ }^{14}$ Results were expressed as the number of neutrophils per five high power fields after correction $\overrightarrow{\dot{x}}$ for background migration. The assay, which has an intra-assay coefficient of variation of $19.5 \%$, was iv performed in duplicate. Calcium ionophore was dis- $\infty$ solved at $10 \mathrm{mmol} / \mathrm{l}$ in dimethyl sulphoxide (BDH) and diluted to specific concentrations in Hanks' balanced salt solution (Flow Laboratories, Rickmans- $\vec{T}$ worth, Herts) containing calcium and magnesium, $\frac{D}{O}$ $30 \mathrm{mM} N$-2-hydroxyethyl-piperazine- $N$-2-ethane sulfonic acid (HEPES) (Sigma) and 0.1\% bovine serum albumin (Sigma). Two $\times 10^{6}$ neutrophils in $500 \mu \mathrm{l}$ of $\vec{c}$ buffer were preincubated at $37^{\circ} \mathrm{C}$ for 10 minutes before $\infty_{\infty}^{\circ}$ the addition of $500 \mu \mathrm{l}$ of buffer containing A23187 to achieve a final concentration of $10 \mu \mathrm{mol} / 1$, or with 500 $\mu \mathrm{l}$ of buffer alone as a control. The mixture was incubated for 10 minutes at $37^{\circ} \mathrm{C}$. The reaction was stopped by rapid cooling on ice and centrifugation at $\frac{2}{1}$ $10000 \mathrm{~g}$ for 30 seconds. The supernatant was removed $\varrho$ and stored at $-20^{\circ} \mathrm{C}$.

Generation of $\mathrm{LTB}_{4}$ and $\mathrm{LTB}_{5}$ was assayed by reverse phase high performance liquid chromatography and radioimmunoassay. ${ }^{1826}$ Briefly, supernatants were applied to a $10 \mu \mathrm{m} \mathrm{C18}$ Ultrasil ODS column $(4.6 \times 250 \mathrm{~mm}$, Beckman Instruments, Berkeley, California). The products were eluted at $1 \stackrel{2}{2}$ $\mathrm{ml} / \mathrm{min}$ in $63 \%$ methanol (BDH), $36.9 \%$ water, $0.1 \% \frac{\mathrm{O}}{3}$ (vol/vol) acetic acid, $\mathrm{pH} 5.6$ for 30 minutes. One millilitre fractions were collected. Duplicate $100 \mu \mathrm{l}$ 윽 samples of each fraction were evaporated to dryness under negative pressure, then each was resuspended in음 $100 \mu$ l of isogel tris buffer and measured for immuno- $\frac{7}{2}$ reactive $\mathrm{LTB}_{4}$ and $\mathrm{LTB}_{5}$ by radioimmunoassay. The column was calibrated for the retention times of $\mathrm{N}^{\mathrm{N}}$ synthetic leukotrienes: LTB $_{5}(12.2$ (SEM 0.4) min, $\mathrm{n}=10) ; \quad(5 S 12 R)-6$-trans LTB $_{4}(15 \cdot 1 \quad(0.5) \mathrm{min}$, 요 $\mathrm{n}=10) ; \quad(5 S, 12 S)-6-$ trans-LTB LT $_{4}(16.0(0.7)$ min, $\omega$ $\mathrm{n}=10) ;$ and LTB $_{4}(19.5(0.9) \min , \mathrm{n}=10)$ Immunoreactive products were identified by a comparison of their retention times with those of the standards. Recoveries of synthetic standards were ${ }^{+}$ similar for all compounds and were over $85 \%$. The recovery of immunoreactive material was $89 \%$ (SEM $\underset{\mathbb{C}}{\vec{C}}$ $2 \%$ ). The $50 \%$ inhibition of binding of $\left[{ }^{3} \mathrm{H}\right]-\mathrm{LTB}_{4}$ to $\frac{\text { T }}{\mathbb{D}}$

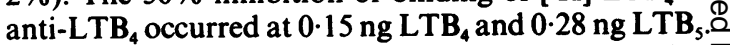
Intra-assay and interassay coefficients of variation? were $7 \%$ and $16 \%$ respectively. 


\section{ANALYSIS OF RESULTS}

Changes in ionophore induced LTB generation by neutrophils were assessed by the Wilcoxon signed rank test. Changes in chemotactic responsiveness of neutrophils to FMLP and to $\mathrm{LTB}_{4}$ were assessed by comparing the whole dose-response curve before and after the diet by analysis of variance. Change in histamine $\mathrm{PD}_{35}$ sGaw was assessed by Student's paired $t$ test on log transformed data.

Changes in airways response to exercise, bronchodilator usage, and morning and evening peak expiratory flow rates were assessed by Student's $t$ test for paired data. Symptom scores were analysed with a randomisation test. All results are expressed as means with standard errors in parentheses unless otherwise stated.

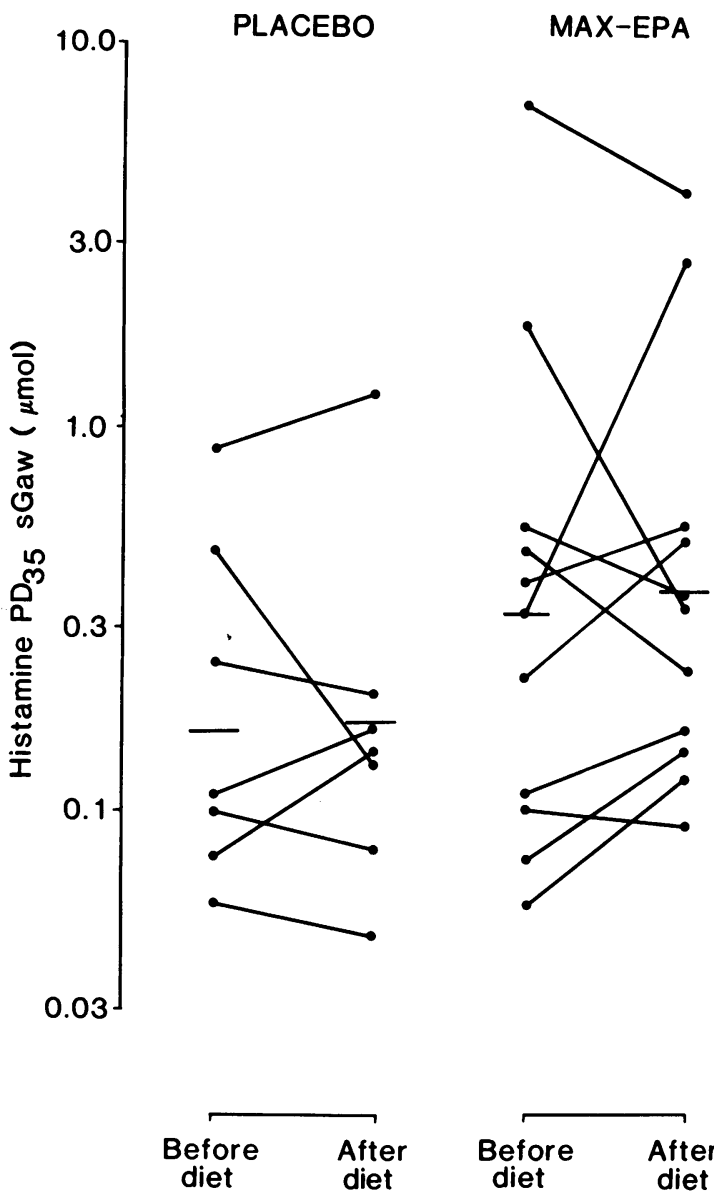

Fig 2 Airways histamine $P D_{35} s G a w$ (dose causing a $35 \%$ fall in specific airways conductance) before and after dietary supplementation with placebo capsules and Max-EPA. - denotes geometric mean. Each point denotes an individual subject.

\section{Results}

Twenty subjects completed the trial. Five individuals did not complete the study: three subjects found the number and size of capsules unmanageable; one subject withdrew from the study owing to personal circumstances; one subject started the study but was withdrawn because three weeks after starting the diet she required admission to hospital for acute asthma. During this period she started taking oral steroids and stopped taking Max-EPA. From the 20 subjects who completed the trial, 12 (six male and 10 atopic, aged 15-41 (mean 25) years) had received Max-EPA and eight subjects (four male, all atopic, aged 19-39 (mean 26) years) had received placebo capsules that did not contain marine fatty acids.

\section{CLINICAL MEASUREMENTS \\ Airways histamine responsiveness}

Histamine responsiveness was assessed in seven "placebo" subjects and 11 subjects receiving MaxEPA. One subject from each treatment group declined to have a second histamine challenge. There was no significant change in baseline sGaw or histamine responsiveness in either group of subjects. Baseline sGaw changed from $1 \cdot 15$ (SEM 0.15) to $1 \cdot 17(0 \cdot 13) \mathrm{s}^{-1}$ $\mathrm{kPa}^{-1}$ after placebo, and from $1.41(0 \cdot 14)$ to $1.50(0 \cdot 15)$ $\mathrm{s}^{-1} \mathrm{kPa}^{-1}$ after Max-EPA. The geometric mean histamine $\mathrm{PD}_{35}$ sGaw changed from $0 \cdot 17$ to $0 \cdot 18 \mu \mathrm{mol}$ after placebo and from 0.32 to $0.37 \mu \mathrm{mol}(\mathrm{p}>0.05)$ after Max-EPA (fig 2). The mean difference in histamine $\mathbf{P D}_{35}$ sGaw between values after Max-EPA and control values before Max-EPA was $0.07 \log$ units $(95 \%$ confidence intervals +0.36 and $-0.22 \log$ units).

\section{Airway response to exercise}

Exercise challenge was performed in five subjects receiving placebo and six receiving Max-EPA. There was no significant difference in the maximal postexertional fall in sGaw before and after placebo or Max-EPA. The maximal percentage decreases in sGaw were 68.2 (SEM 2.9) and 69.2 (4.7) before and after placebo and $55.5(5 \cdot 5)$ and $56.5(3.6)$ before and after Max-EPA.

\section{Diary cards}

Diary cards were available for analysis from five subjects receiving placebo and 12 receiving Max-EPA. Three subjects receiving placebo lost their diary cards during the study. There was no significant change in any of the clinical indices assessed after either the placebo or the Max-EPA supplemented diet (table 1).

The clinical responses of patients having inhaled corticosteroids did not differ significantly from those of subjects not receiving these drugs. 
Table 1 Mean (SEM) diurnal peak expiratory flow rates, airways lability, symptom scores, and bronchodilator use in the two weeks before and the last two weeks of dietary supplementation with placebo and Max-EPA*

\begin{tabular}{|c|c|c|c|c|c|}
\hline & \multicolumn{2}{|c|}{ Placebo $(n=5)$} & \multicolumn{2}{|c|}{$\operatorname{Max}-E P A(n=12)$} & \multirow[b]{2}{*}{ Mean difference (95\% CL) } \\
\hline & Before & After & Before & After & \\
\hline $\begin{array}{l}\text { Morning peak flow }\left(1 \mathrm{~min}^{-1}\right) \\
\text { Evening peak flow }\left(1 \mathrm{~min}^{-1}\right) \\
\text { Lability (\%) } \\
\text { Symptoms (total score) } \\
\text { Bronchodilator use (total number } \\
\text { of doses) }\end{array}$ & $\begin{array}{l}426(41) \\
438(43) \\
7 \cdot 5(1 \cdot 0) \\
5 \cdot 8(3 \cdot 0) \\
63 \cdot 2(21 \cdot 6)\end{array}$ & $\begin{array}{c}430(39) \\
437(43) \\
6 \cdot 7(0 \cdot 9) \\
8 \cdot 3(2 \cdot 3) \\
55 \cdot 0(16 \cdot 8)\end{array}$ & $\begin{array}{l}494(24) \\
505(26) \\
4 \cdot 7(0 \cdot 61) \\
10 \cdot 9(3 \cdot 6) \\
31 \cdot 8(9 \cdot 4)\end{array}$ & $\begin{array}{l}499(26) \\
503(24) \\
4 \cdot 6(1 \cdot 1) \\
14 \cdot 1(3 \cdot 2) \\
39 \cdot 6(12 \cdot 6)\end{array}$ & $\begin{array}{l}+5(+26,-16) \\
-2(+16,-19) \\
-0 \cdot 1(+2 \cdot 3,-2 \cdot 6) \\
+3 \cdot 2(+13 \cdot 0,-6 \cdot 7) \\
+7 \cdot 8(+20,-4 \cdot 4)\end{array}$ \\
\hline
\end{tabular}

${ }^{*}$ Contains $3 \cdot 2 \mathrm{~g}$ eicosapentaenoic acid and $2 \cdot 2 \mathrm{~g}$ docosahexaenoic acid. CL-confidence limits.

\section{NEUTROPHIL STUDIES}

Neutrophil phospholipid fatty acid composition

The fatty acid content of neutrophil phospholipids was assessed in all subjects. Arachidonic acid, eicosapentaenoic acid, and docosahexaenoic acid comprised $12.9 \%$ (SEM $3.7 \%$ ), $0.1 \%(0.1 \%)$, and $2.8 \%(0.7 \%)$ of the total neutrophil fatty acid content of subjects before dietary supplementation with placebo capsules, and $14 \cdot 6 \%(2 \cdot 7 \%), 0 \cdot 2 \%(0 \cdot 1 \%)$, and $2.2 \%(0.6 \%)$ in subjects before supplementation with Max-EPA. The neutrophil eicosapentaenoic acid content remained unchanged after placebo capsules, but rose to $2.6 \%(0.5 \%)$ of total neutrophil fatty acids after Max-EPA. There was no significant change in neutrophil arachidonic acid or docosahexaenoic acid content in either group (table 2).

\section{Calcium ionophore induced generation of LTB compounds}

Calcium ionophore induced generation of $\mathrm{LTB}_{4}$ and $\mathrm{LTB}_{5}$ was assessed in six subjects receiving placebo and 11 receiving Max-EPA because of the limitation in cell numbers. There was no significant change in $\mathbf{L T B}_{4}$ generation in the placebo group after olive oil supplementation (control values 10.7 (SEM 3.4) $\mathrm{ng} / 2 \times 10^{6}$ neutrophils; after the diet $10.9(3.0)$ $\mathrm{ng} / 2 \times 10^{6}$ neutrophils; $\left.\mathrm{p}>0.05\right)$. In subjects who had taken Max-EPA generation of LTB compounds 을 was attenuated by $48 \%$ (control $15.3(6.0) \mathrm{ng} / 2 \times 10^{6}-$ neutrophils; after the diet $8.0(2.8) \mathrm{ng} / 2 \times 10^{6}$ neutro- $\mathbb{D}$ phils, p $<0.01$ ). No LTB $_{s}$ was generated by ionophore activated neutrophils before either dietary period or after treatment with placebo. After dietary supplementation with Max-EPA $10 \mu \mathrm{M}$ calcium ionophore stimulated neutrophils to generate $1.8(0.6) \mathrm{ng}$ of $\mathrm{LTB}_{5} / 2 \times 10^{6}$ neutrophils (table 3 ).

\section{Neutrophil chemotaxis}

Because cells were limited neutrophil chemotactic $\stackrel{\unrhd}{\mathscr{Q}}$ responsiveness to FMLP was assessed in five subjects $\overrightarrow{\vec{A}}$ receiving placebo and 10 receiving Max-EPA, and $\frac{9}{3}$ responsiveness to $\mathrm{LTB}_{4}$ in four receiving placebo and six receiving Max-EPA. The chemotactic responsiveness of neutrophils to both agonists was unchanged after 10 weeks of placebo treatment. After 10 weeks of 음 Max-EPA there was a substantial and consistent $\underset{\varnothing}{\varnothing}$ attenuation of the chemotactic responses to both 0 FMLP $(p=0.01)$ and $\operatorname{LTB}_{4}(\mathrm{p}=0.04)$. The maximal chemotactic response to $10^{-7} \mathrm{~mol}$ FMLP and $10^{-6} \mathrm{~mol} \stackrel{\mathrm{\delta}}{\mathrm{C}}$ LTB $_{4}$ decreased from 115 (SEM 39) and 121 (53) neutrophils/ 5 high power fields (hpf) before the diet to $\frac{\text { ㅇ }}{5}$ 54 (14) and 52 (19) neutrophils/5 hpf after Max-EPA (figs 3 and 4 ).

Table 2 Mean (SEM) fatty acid composition of neutrophil extracts, expressed as a percentage of total fatty acid content, before and after dietary supplementation with placebo and Max-EPA*

\begin{tabular}{|c|c|c|c|c|}
\hline & \multicolumn{4}{|c|}{ Fatty acids } \\
\hline & $\begin{array}{l}\text { 18:2 } \\
\text { linoleic }\end{array}$ & $\begin{array}{l}20: 4 \\
\text { arachidonic }\end{array}$ & $\begin{array}{l}20: 5 \\
\text { eicosapentaenoic }\end{array}$ & $\begin{array}{l}22: 6 \\
\text { docosahexaenoic }\end{array}$ \\
\hline $\begin{array}{l}\text { Placebo }(n=8) \\
\text { Before } \\
\text { After }\end{array}$ & $\begin{array}{l}5.9(1 \cdot 5) \\
6.9(1 \cdot 3)\end{array}$ & $\begin{array}{l}12.9(3.7) \\
13.5(2.8)\end{array}$ & $\begin{array}{l}0.1(0.1) \\
0.1(0.1)\end{array}$ & $\begin{array}{l}2.8(0.7) \\
1.9(0.4)\end{array}$ \\
\hline $\begin{array}{l}\text { Max-EPA }(n=12) \\
\text { Before } \\
\text { After }\end{array}$ & $\begin{array}{l}7.0(1.2) \\
6.7(1.0)\end{array}$ & $\begin{array}{l}14 \cdot 6(2 \cdot 7) \\
13 \cdot 3(1 \cdot 3)\end{array}$ & $\begin{array}{l}0 \cdot 2(0 \cdot 1) \\
2 \cdot 6(0 \cdot 5)\end{array}$ & $\begin{array}{l}2 \cdot 2(0 \cdot 6) \\
2 \cdot 6(0.3)\end{array}$ \\
\hline
\end{tabular}


Table 3 Generation of leukotriene B compounds ( $L T B_{4}$ and $L T B_{s}$ ) from ionophore stimulated neutrophils (means (SEM)) before and after dietary supplementation with placebo and Max-EPA*

\begin{tabular}{|c|c|c|c|}
\hline & \multicolumn{3}{|c|}{ Quantity of product $\left(\mathrm{ng} / 2 \times 10^{6}\right.$ neutrophils } \\
\hline & $\begin{array}{l}\text { Total LTB } \\
\text { Compounds }\end{array}$ & $L T B_{4}$ & $L T B_{5}$ \\
\hline \multicolumn{4}{|c|}{ Placebo $(n=6)$} \\
\hline Before & $10 \cdot 7(3.4)$ & $10 \cdot 7(3 \cdot 4)$ & ND \\
\hline After & $10.9(3.0)$ & $10.9(3.0)$ & ND \\
\hline \multicolumn{4}{|c|}{$\operatorname{Max}-\operatorname{EPA}(\mathrm{n}=11)$} \\
\hline $\begin{array}{l}\text { Before } \\
\text { After }\end{array}$ & $\begin{array}{r}15 \cdot 3(6 \cdot 0) \\
8 \cdot 0(2 \cdot 8)\end{array}$ & $\begin{array}{r}15 \cdot 3(6 \cdot 0) \\
6 \cdot 2(2 \cdot 5)\end{array}$ & $\begin{array}{l}\text { ND } \\
(1 \cdot 8)(0 \cdot 6)\end{array}$ \\
\hline
\end{tabular}

*See table 1.

ND not detected.

\section{Discussion}

Both eicosapentaenoic acid and docosahexaenoic acid are prominent in fish oil enriched diets. Eicosapentaenoic acid is a better substrate and docosahexaenoic acid is a substantially worse substrate for product generation by the 5-lipoxygenase pathway than is arachidonic acid. ${ }^{27}$ Docosahexaenoic acid has little effect on arachidonic acid metabolism by the 5lipoxygenase pathway, whereas eicosapentaenoic acid leads to the elaboration of less $\mathrm{LTB}_{4}{ }^{12}$ and yields a structurally analogous product $\mathrm{LTB}_{5}$, which has reduced biological activity. ${ }^{14-15}$ Dietary supplementation with fish oil in the form of Max-EPA for six weeks in normal individuals led to the incorporation of eicosapentaenoic acid into the membrane lipids of inflammatory leucocytes, suppressed the generation of $\mathrm{LTB}_{4}$ by the 5-lipoxygenase pathway, ${ }^{182}$ and inhibited neutrophil functional responses mediated by this leukotriene. $^{18}$ Since bronchial inflammation and infiltrating leucocytes may be important in the pathogenesis of asthma, ${ }^{1-9}$ we have studied the effects of inhibition of neutrophil function through the provision of fish oil lipids on non-specific airway hyperresponsiveness and the severity of asthma.

The study was conducted in a placebo controlled and double blind manner and carried out with a parallel rather than a crossover design because we could not predict the duration of any clinical effect of dietary supplementation with eicosapentaenoic acid. The fish oil lipids were provided in the form of MaxEPA, which consists mainly of triglycerides, with $34 \%$ of the total fatty acids and $86 \%$ of the polyunsaturated fatty acids consisting of eicosapentaenoic acid and docosahexaenoic acid. The dose of eicosapentaenoic acid we selected for study is the dose that has previously been shown to have anti-inflammatory potential on the basis of its effect on leucocyte function. ${ }^{18}$

The airway responses to histamine and exercise were used to assess changes in non-specific bronchial responsiveness during dietary supplementation with fish oil lipids. In addition, symptom scores, bronchodilator use, and airway lability as measured by diurnal variations in peak flow were carefully
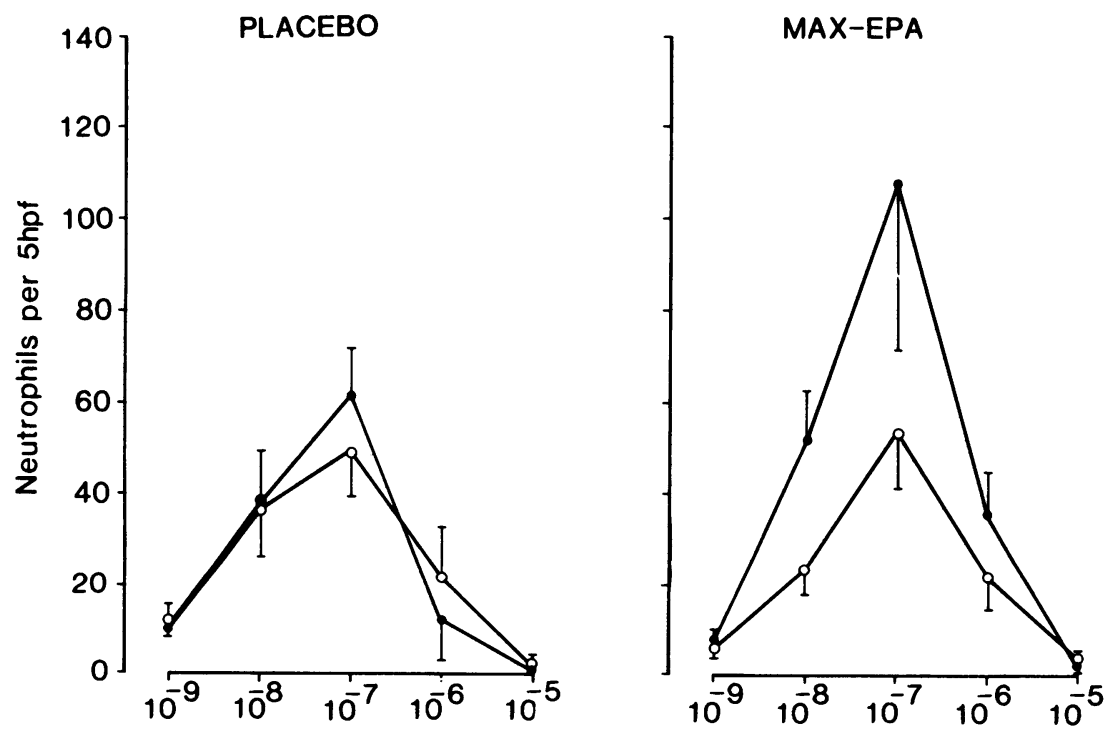

Fig 3 Chemotactic responses of neutrophils to formyl methionyl leucyl phenylalanine (FMLP) before (O) and after (O) placebo and Max-EPA. Chemotactic responses are expressed as the number of neutrophils per 5 high powered fields (hpf). Each point is the mean (SEM) of five in the placebo and 10 in the Max-EPA group. 

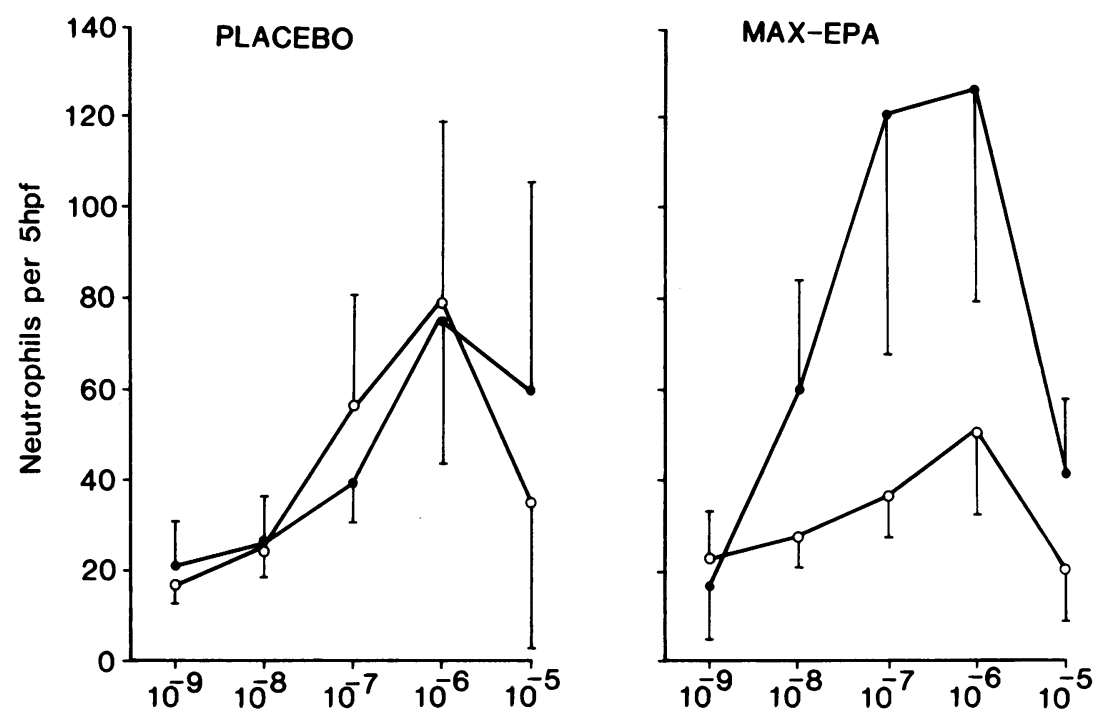

Fig 4 Chemotactic responses of neutrophils to leukotriene $B_{4}$ $\left(L T B_{4}\right)$ before $(\bullet)$ and after (O) placebo and Max-EPA. Each point is the mean (SEM) of four subjects in the placebo and six in the Max-EPA group.

LTB, Concentration ( $\mathrm{mol} / \mathrm{l})$

documented. There was no significant change in any of the clinical variables assessed after either the placebo or the Max-EPA supplemented diet over the period of the study, despite a greater than 10 fold increase in the eicosapentaenoic acid content of neutrophil phospholipids in individuals given Max-EPA and barely detectable eicosapentaenoic acid in subjects given placebo capsules.

Incorporation of eicosapentaenoic acid into neutrophil membrane phospholipids was analysed by the sensitive and precise technique of gas chromatography. Neutrophil functional responses were assessed by studying the generation of LTB products in cells stimulated by the calcium ionophore and by assessing the chemotactic responsiveness of the same target cells. Previous work had already indicated that eicosapentaenoic acid inhibits the generation of $\mathrm{LTB}_{4}$ from neutrophils and monocytes stimulated by calcium ionophore in a dose and time dependent manner. ${ }^{12-18}$ Thus in this study the effect of eicosapentaenoic acid was evaluated only with neutrophils that had been stimulated with the ionophore under optimal conditions of dose and time. The calcium ionophore was chosen to bypass membrane calcium gating mechanism $\mathrm{s}^{28}$ and to give a true measure of the integrity of the 5-lipoxygenase pathway. LTB $_{4}$ and LTB $_{5}$ were measured in neutrophil supernatants after RP-HPLC by means of a sensitive and specific radioimmunoassay. ${ }^{26}$ The $\mathrm{RP}$-HPLC and radioimmunoassays had been calibrated by authentic reference standards of the relevant leukotrienes and these had been prepared by total organic synthesis. ${ }^{290}$
The capacity of neutrophils to produce $\mathrm{LTB}_{4}$ was reduced by about half after dietary supplementation with Max-EPA, but showed no change with placebo. These results extend previous work on normal subjects. ${ }^{18}$ Since eicosapentaenoic acid does not increase catabolism of $\mathrm{LTB}_{4}{ }^{12}$ this attenuation of LTB $_{4}$ generation was attributed to inhibition of biosynthesis.

Since the recruitment of leucocytes to a focus of inflammation by chemotactic factors is likely to have a central role in the amplification of the inflammatory process, we assessed the chemotactic responsiveness of the leucocytes to one or both of two transmembrane and receptor mediated chemotactic agonists-namely, FMLP and $\mathrm{LTB}_{4}$. Neutrophil chemotactic responsiveness was not evaluated in all individuals because of the limited number of cells. Nevertheless, each subject acted as his own control and the data were consistent within each group. The chemotactic responsiveness $\mathcal{N}$ of neutrophils to both FMLP and LTB $_{4}$ was sub- N stantially inhibited after Max-EPA dietary supple- N mentation and this was not observed in the placebo group. Since neutrophil chemotaxis is likely to be of fundamental importance in the development of inflammatory processes, eicosapentaenoic acid can be $\stackrel{\infty}{\rightarrow}$ regarded as anti-inflammatory.

The results of this study indicate that neutrophil function can be suppressed without changing the severity of asthma in patients with mild disease. These results are similar to those of Kirsch et al, who have also shown no benefit from a fish oil enriched diet in patients with severe, chronic, and persistent asthma, 
despite a substantial attenuation of neutrophil chemotactic responsiveness to $\mathrm{LTB}_{4}, \mathrm{FMLP}$, and complement $\mathrm{C} 5 \mathrm{a}^{31}{ }^{32}$ These results are consistent with the view that neutrophils do not play a major part in the pathogenesis of asthma or alternatively that, if neutrophils have a role in the mechanisms of asthma, their functions were not suppressed adequately for a clinical effect to be apparent. Although we have shown substantial changes in the in vitro functions of circulating neutrophils, these functions may not be relevant to the physiological events that occur in airways inflammation. In addition, inflammatory mediators other than arachidonic acid derived metabolites and other cell types, such as eosinophils and alveolar macrophages, may play a part in amplifying the inflammatory changes observed in asthmatic airways. There is no information on how these mediators and cells are affected by the fish oil enriched diet. Finally, although 10 weeks of dietary supplementation with fish oil lipids led to a substantial suppression of neutrophil function, this period may not have been enough for regeneration of airways epithelium and resolution of the chronic inflammatory response to effect a change in clinical variables. We have shown that 10 weeks' dietary supplementation with MaxEPA suppresses neutrophil function but fails to alter airways responsiveness and the severity of asthma in individuals with mild disease.

This work was supported in part by the Asthma Research Council, and the International Association of Fish Meal Manufacturers. The authors are grateful to Dr J Rokach for the gift of $\mathrm{LTB}_{4}$ antiserum and to Seven Seas Ltd, Marfleet, Hull, for the Max-EPA and matched placebo capsules.

\section{References}

1 Marsh WR, Irvin CG, Murphy KR, Behrens BL, Larsen GL. Increases in airway reactivity to histamine and inflammatory cells in bronchoalveolar lavage after the late asthmatic response in an animal model. Am Rev Respir Dis 1985;131:857-79.

2 Murphy KR, Wilson MC, Irvin CG, et al. The requirement for polymorphonuclear leukocytes in the late asthmatic response and heightened airways reactivity in an animal model. Am Rev Respir Dis 1986;134:62-8.

3 Chung KF, Becker AB, Lazarus SC, Frick OL, Nadel JA, Gold WM. Antigen-induced airway hyperresponsiveness and pulmonary inflammation in allergic dogs. $J$ Appl Physiol 1985;58:1347-53.

4 Cartier A, Thomson NC, Frith PA, Roberts R, Hargreave FE. Allergen-induced increase in bronchial responsiveness to histamine: relationship to the late asthmatic response and change in airway calibre. $J$ Allergy Clin Immunol 1982;70:170-7.

5 De Monchy JGR, Kauffman HF, Venge P, et al. Bron- choalveolar eosinophilia during allergen-induced late asthmatic reactions. Am Rev Respir Dis 1985;131: 373-6.

6 Metzger WJ, Richerson HB, Worden K, Monick M, Hunninghake GW. Bronchoalveolar lavage of allergic asthmatic patients following allergen bronchoprovocation. Chest 1986;89:477-83.

7 Fabbri LM, Aizawa H, Alpert SE, et al. Airway hyperresponsiveness and changes in cell counts in bronchoalveolar lavage after ozone exposure in dogs. $\mathrm{Am}$ Rev Respir Dis 1984;129:288-91.

8 Stelzer J, Geffroy B, Stalborg M, Holtzman MJ, Nadel JA, Boushey HA. Association between airway inflammation and changes in bronchial reactivity induced by ozone exposure in healthy subjects [abstract]. Am Rev Respir Dis 1984;129:A262.

9 O'Byrne PM, Leikauf GD, Aizawa $\mathrm{H}$, et al. Leukotriene $\mathrm{B}_{4}$ induces airway hyperresponsiveness in dogs. $\mathrm{J} \mathrm{Appl}$ Physiol 1985;59:1941-6.

10 Corey EJ, Shih C, Cashman JR. Docosahexaenoic acid is a strong inhibitor of prostaglandin but not leukotriene biosynthesis. Proc Natl Acad Sci USA 1983;80:3581-4.

11 Prescott SM. The effect of eicosapentaenoic acid on leukotriene B production by human neutrophils. J Biol Chem 1984;259:7615-21.

12 Lee TH, Mencia-Huerta JM, Shih C, Corey EJ, Lewis RA, Austen KF. Effects of exogenous arachidonic, eicosapentaenoic and docosahexaenoic acids on the generation of 5-lipoxygenease pathway products by ionophore-activated human neutrophils. J Clin Invest 1984;74:1922-33.

13 Needleman P, Raz A, Minkes NS, Ferendelli A, Sprecher H. Triene prostaglandins: prostacyclin and thromboxane biosynthesis and unique biological properties. Proc Natl Acad Sci USA 1979;76:944-8.

14 Lee TH, Mencia-Huerta JM, Shih C, Corey EJ, Lewis RA, Austen KF. Characterization and biologic properties of 5,12-dihydroxy derivatives of eicosapentaenoic acid including leukotrienes $B_{5}$ and the double lipoxygenase product. $J$ Biol Chem 1984;259:2383-9.

15 Terano T, Salmon JA, Moncada S. Biosynthesis and biological activity of leukotriene $\mathrm{B}_{5}$. Prostaglandins 1984;27:217-32.

16 Dahlen SE, Hedquist P, Hammarstrom S. Contractile activities of several cysteine-containing leukotrienes in the guinea pig lung strip. Eur $J$ Pharmacol 1982;86:207-15.

17 Goldman DW, Pickett WC, Goetzl EJ. Human neutrophil chemotactic and degranulating activities of leukotriene $\mathrm{B}_{5}\left(\mathrm{LTB}_{5}\right)$ derived from eicosapentaenoic acid. Biochem Biophys Res Commun 1983;117:282-8.

18 Lee TH, Hoover RL, Williams JD, et al. Effect of dietary enrichment with eicosapentaenoic and docosahexaenoic acids on in vitro neutrophil and monocyte leukotriene generation and neutrophil function. $N$ Engl J Med 1985;312:1217-24.

19 Prickett JD, Robinson DR, Steinberg AD. Dietary enrichment with the polyunsaturated fatty acid eicosapentaenoic acid prevents proteinuria and prolongs survival in NZB $\times \mathrm{NZW} \mathrm{F}_{1}$ mice. $J$ Clin Invest 1981;68:566-9.

20 Robinson DR, Prickett JD, Makoul GT, Steinberg AD, 
Colvin RB. Dietary fish oil reduces progression of established renal disease in (NZB $\times \mathrm{NZW}) \mathrm{F}_{1}$ mice and delays renal disease in BxSB and MRL/L strains. Arthritis Rheum 1986;29:539-46.

21 Kremer JM, Jubiz W, Michalek, A, et al. Fish oil fatty acid supplementation in active rheumatoid arthritis. Ann Intern Med 1987;106:497-503.

22 Eiser NM, Mills J, McRae KD, Snashall PD, Guz A. Histamine receptors in normal human bronchi. Clin Sci 1980;58:537-44.

23 Chowienczyk PJ, Rees PJ, Payne J, Clark TJH. A new method for computer-assisted determination of airways resistance. J Appl Physiol 1981;50:672-8.

24 Boyum A. Isolation of mononuclear cells and granulocytes from human blood. Scand J Clin Lab Invest 1968;21 (suppl 97):77-89.

25 Bligh EG, Dyer WJ. A rapid method of total lipid extraction and purification. Can J Biochem Physiol 1959;37:911-7.

26 Rokach J, Hayes EC, Girard Y, et al. The development of sensitive and specific radioimmunoassays for leukotrienes. Prostaglandins Leukotrienes Med 1984;
13:21-5.

27 Ochi K, Yoshimoto T, Yamamoto T, Taniguchi K, Miyamoto T. Arachidonate 5-lipoxygenase of guinea pig peritoneal polymorphonuclear leukocytes: activation by adenosine 5 '-triphosphate. J Biol Chem 1983;258:5754-8.

28 Foreman JC, Mongar JL, Gomperts BD. Calcium iono- ® phores and movement of calcium ions following the $\vec{\nabla}$ physiological stimulus to a secretory process. Nature 1973;245:249-51.

29 Corey EJ, Marfat A, Goto G, Brion F. Leukotriene B, total synthesis and assignment of stereochemistry. $J$ Am Chem Soc 1981;102:7984-6.

30 Corey EJ, Pyne SG, Su Wei-guo. Total synthesis of leukotriene $B_{5}$. Tetrahedron Letters 1983;24:4883-6.

31 Payan DG, Wong YS, Chernov-Rogan T, et al. Altera- $\stackrel{\infty}{\perp}$ tions in human leukocyte function induced by inges- 은 tion of eicosapentaenoic acid. J Clin Immunol 1986;78:937-42.

32 Kirsch CM, Payan DG, Wong MYS, et al. The effect of eicosapentaenoic acid in asthma. Clin Allergy (in press). 